\title{
Effect of follicular fluid supplementation during in vitro maturation on total cell number in bovine blastocysts produced in vitro
}

\author{
Maria Helena Coelho Cruz ${ }^{1}$, Naiara Zoccal Saraiva ${ }^{1}$, Jurandir Ferreira da Cruz ${ }^{2}$, Clara Slade \\ Oliveira ${ }^{1}$, Maite Del Collado ${ }^{1}$, Hugo Fernandes ${ }^{3}$, Fernanda Cavallari de Castro ${ }^{3}$, \\ Joaquim Mansano Garcia ${ }^{1}$
}

\footnotetext{
${ }^{1}$ Departamento de Medicina Veterinária Preventiva e Reprodução Animal, Universidade Estadual Paulista "Júlio de Mesquita Filho", Jaboticabal, SP, Brasil.

${ }^{2}$ Laboratório de Reprodução de Caprinos e Ovinos, Universidade Estadual do Sudoeste da Bahia, Vitória da Conquista, BA, Brasil.

${ }^{3}$ Departamento de Ciências Básicas, Universidade de São Paulo, Pirassununga, SP, Brasil.
}

\begin{abstract}
This study evaluated the influence of follicular fluid (FF) added to the maturation medium on the quality of bovine embryos produced in vitro. In the first experiment, oocytes were matured in media containing five different $\mathrm{FF}$ concentrations with different maturation times and classified according to meiotic progression and migration of cortical granules. In the second experiment, oocytes matured in the same media were fertilized at three different maturation times; thereafter, cleavage and blastocyst rates were evaluated. In the third experiment, oocytes were matured in media containing three different FF concentrations at two different maturation times, and embryo quality, inferred by the ratio of inner cell mass and trophectoderm cells compared with total cell number, was evaluated. Higher FF concentration $(75-100 \%$ FF) slowed meiotic progression and CG migration (control - $78.13 \%$ vs. treated $-52.58 \%$ and control $-52.7 \%$ vs. treated $-11.59 \%$, respectively, at $24 \mathrm{~h}$ of maturation). Also, FF at concentration of $75 \%$ or $100 \%$ had a negative influence on cleavage and blastocyst rates (control $-90.13 \%$ vs. treated $-82.64 \%$ and control $-35.73 \%$ vs. treated $-11.57 \%$, respectively, at 24 h of maturation). The $50 \%$ FF resulted in embryos with increased inner cell mass numbers (control - 29.91 vs. treated - 35.49, at $24 \mathrm{~h}$ of maturation) and total cell numbers (control - 109.53 vs. treated - 120.67, at $26 \mathrm{~h}$ of maturation). Even though higher concentration of $\mathrm{FF}$ added to the maturation medium reduced embryonic development rates, in lower concentrations, FF slowed the meiotic progression and migration of CG and contributed to increases in inner cell mass number. Thus, FF added to the maturation medium enhances the number of cells in bovine embryos produced in vitro, especially for inner cell mass.
\end{abstract}

Key Words: embryo development, inner cell mass, in vitro fertilization, oocytes

\section{Introduction}

The oocyte maturation process involves the activation and inhibition of enzymes, hormones and growth factors, which results in nuclear and cytoplasmic maturation (Gilchrist and Thompson, 2007). Nuclear maturation occurs spontaneously, and mechanical removal of the oocyte from the follicle is capable of triggering the process, but cytoplasmic maturation occurs more gradually (Brevini et al., 2007).

There are clear differences regarding embryonic development, particularly between oocytes matured in vitro and those matured in vivo (Choi et al., 1998). Numerous studies have shown that under in vitro conditions, the nuclear and cytoplasmic maturation occurs at different times (Sirard et al., 1995; Bevers et al., 1997), which might be the cause of blastocyst rates around 35\% observed for in vitro production of bovine embryos (Rizos et al., 2002), and lower embryo quality compared with embryos produced in vivo (Gonçalves et al., 2008).

The identification of substances capable of delaying the nuclear maturation time and thus allowing cytoplasmic and nuclear changes to occur synchronously has been the subject of several studies (Liu et al., 2003; Hussein et al., 2006; Sirard et al., 2007; Albuz et al., 2010). Follicular fluid (FF), consisting of electrolytes, hormones, amino acids, growth factors, among other components, has been used as a natural substance for blocking the meiosis (Aguilar et al., 2001). Some studies have documented that maturation medium supplemented with FF provides appropriate environment to bovine oocyte development (Romero-Arredondo and Seidel, 1996), since it increases the degree of cumulus cells expansion (Aguilar et al., 2001) and enhances the embryonic development (Algriany et al., 2004).

There is still controversy about the real contribution of FF to embryonic development. Follicular fluid as a maturation 
medium is sufficient to promote nuclear maturation; however, it presents limitations to support appropriate embryo development (Avery et al., 2003; Coleman et al., 2007). Due to the inhibitory effect on germinal vesicle breakdown and on meiotic progression, FF leads to a delay on the nuclear maturation (Ducolomb et al., 2013). In this sense, the identification of the optimal time for fertilization of oocytes matured in FF might improve output and quality of blastocyst. Thus, to increase understanding about the action of this fluid on in vitro development of oocytes and embryos, the present study evaluated the influence of FF on the nuclear and cytoplasmic maturation and the quality of bovine embryos produced in vitro.

\section{Material and Methods}

Reagents and culture media were purchased from Sigma Chemical Co. (St. Louis, MO) unless otherwise stated. Three experiments were designed. The first experiment evaluated oocytes subjected to in vitro culture media (TCM 199) containing five different FF concentrations $(0,25,50$, 75 and $100 \% \mathrm{FF})$ in four maturation times $(22,24,26$ or $28 \mathrm{~h}$ ), with six replicates, to verify the influence of FF on oocyte maturation. In experiment II, we evaluated the same culture media from experiment I and three fertilization moments $(24,26$ or $28 \mathrm{~h}$ of in vitro maturation - IVM), with six replicates, aiming to analyze the effect of FF on embryonic development.

Considering the lower rates for embryonic development when in vitro fertilization (IVF) was performed at $28 \mathrm{~h}$ of in vitro maturation (IVM), in Experiment III we evaluated the quality of embryos at two moments of fertilization (24 and 26 h), with three replicates. Ovaries obtained postmortem from adult cattle, slaughtered at a local abattoir, were transported to the laboratory in $0.9 \%$ saline at $30-35{ }^{\circ} \mathrm{C}$. The follicles between 8 to $15 \mathrm{~mm}$ in diameter, with a clear appearance and a good blood supply, were aspirated with a 20 -gauge needle connected to a $20 \mathrm{~mL}$ syringe. The aspirated fluid was placed in a polystyrene tube containing $50 \mathrm{IU}$ of sodium heparin and centrifuged at 2,840 $\mathrm{g}$ for $7 \mathrm{~min}$. The supernatant was filtered through a $0.20 \mu \mathrm{m}$ membrane, placed into microtubes $(1.0 \mathrm{~mL})$ and stored at $-20^{\circ} \mathrm{C}$ until use.

Follicles measuring 3 to $8 \mathrm{~mm}$ in diameter were aspirated and the cumulus-oocyte complexes (COC) recovered were washed in HEPES-buffered TCM-199 (Gibco BRL, Grand Island, NY) supplemented with 10\% fetal bovine serum (FBS; Cripion, Andradina, Brazil), $16 \mu \mathrm{g} / \mathrm{mL}$ sodium pyruvate and $83.4 \mu \mathrm{g} / \mathrm{mL}$ amikacin (Instituto Biochimico, Rio de Janeiro, Brazil) and classified according to morphological appearance. Groups of $15 \mathrm{COC}$ were transferred to $100 \mu \mathrm{L}$ drops of medium containing sodium bicarbonate-buffered TCM-199 supplemented with $10 \% \mathrm{FBS}, 1.0 \mu \mathrm{g} / \mathrm{mL}$ FSH (Folltropin ${ }^{\mathrm{TM}}$, Bioniche Animal Health, Belleville, Canada), $50 \mu \mathrm{g} / \mathrm{mL}$ hCG (Profasi ${ }^{\mathrm{TM}}$, Serono, Sao Paulo, Brazil), $1.0 \mu \mathrm{g} / \mathrm{mL}$ estradiol, $16 \mu \mathrm{g} / \mathrm{mL}$ sodium pyruvate and $83.4 \mu \mathrm{g} / \mathrm{mL}$ amikacin, covered with sterile mineral oil (Dow Corning Co., Midland, MI) and incubated at $38.5{ }^{\circ} \mathrm{C}$ in humidified air containing $5 \% \mathrm{CO}_{2}$ under saturated humidity, for various maturation times, based on the specific experiment.

The nuclear maturation rate (NMR) was determined by meiotic progression. For the assessment of nuclear progression to metaphase II stage, the oocytes were stripped off cumulus cells with $0.2 \%$ hyaluronidase (Hyalozima ${ }^{\circledR}$, Aspen, CO, USA) in phosphate buffered saline without $\mathrm{Ca}^{2+}$ and $\mathrm{Mg}^{2+}$ (PBS $\mathrm{Ca}^{2+}$ and $\mathrm{Mg}^{2+}$ free) and stained with $10 \mu \mathrm{g} / \mathrm{mL}$ Hoechst 33342, using the method described by Cherr et al. (1988), with modifications. The cytoplasmic maturation rate (CMR) was determined by cortical granules (CG) migration. To evaluate the migration of $\mathrm{CG}$ to the periphery of the cytoplasm, the zona pellucida was removed from the denuded oocytes with Tyrode's solution ( $\mathrm{pH} 2.5$ ). For permeabilization, oocytes were treated for $3 \mathrm{~min}$ at $38{ }^{\circ} \mathrm{C}$ in blocking solution (SB) plus $0.1 \%$ Triton X-100 (USB, Cleveland, OH, USA). Subsequently, they were incubated for $15 \mathrm{~min}$ at $38{ }^{\circ} \mathrm{C}$ in $10 \mu \mathrm{g} / \mathrm{mL}$ fluorescein isothiocyanate-conjugated Lens culinaris agglutinin. This lecithin specifically binds $\alpha$-D-mannose present in CG. For assessment of cytoplasmic maturation, oocytes were classified according to the distribution of $\mathrm{CG}$, following the classification of Hosoe and Shioya (1997).

The semen used for the study was obtained from a single bull. The frozen straws $(0.25 \mathrm{~mL})$ were thawed at the time of use at $37^{\circ} \mathrm{C}$ for $30 \mathrm{~s}$ and semen was deposited on Percoll gradient $45-90 \%$, and centrifuged at $3,600 \mathrm{~g}$ for $7 \mathrm{~min}$. The pellet was resuspended in $500 \mu \mathrm{L}$ IVF-TALP supplemented with $0.6 \% \mathrm{BSA}, 10 \mathrm{mg} / \mathrm{mL}$ heparin, $18 \mu \mathrm{M}$ penicillamine, $10 \mu \mathrm{M}$ hypotaurine and $1.8 \mu \mathrm{M}$ epinephrine, and covered with sterile mineral oil to form a new pellet after centrifugation at $520 \mathrm{~g}$ for $5 \mathrm{~min}$. After centrifugation, the pellet was collected from the bottom of the tube, at a final concentration of approximately $10^{4}$ spermatozoa for each oocyte.

The matured oocytes were transferred in groups of 20-25 per fertilization drop (IVF-TALP). These were coincubated with spermatozoa for $18-20 \mathrm{~h}\left(38.5^{\circ} \mathrm{C}\right.$, humidified air containing $5 \% \mathrm{CO}_{2}$ ) for fertilization. Presumptive zygotes were denuded by vigorous pipetting for removal of cumulus cells and spermatozoa. Then the embryos were washed three times in SOF medium supplemented with $2.5 \% \mathrm{FCS}$ and $5 \mathrm{mg} / \mathrm{mL} \mathrm{BSA}$, and transferred to the 
in vitro culture (IVC) dish, with droplets containing $100 \mu \mathrm{L}$ development medium, and cultured $\left(38.5^{\circ} \mathrm{C}\right.$ in humidified air containing $5 \% \mathrm{CO}_{2}$ ) for six days. In the third and fifth days of culture, approximately $50 \%$ of the drop medium was removed and an equal volume of fresh medium was added.

The cleavage rate (CR) was determined 32-36 hours after insemination, using a stereomicroscope (50 X). Zygotes that had two or more cells were considered cleaved. The blastocyst rate (BR) was determined on the seventh day after IVF. The quality of blastocysts was evaluated by the inner cell mass (ICM) and trophectoderm (TE) cell number. The identification of ICM and TE, for subsequent quantification, was based on the modified technique for differential fluorochrome staining. The blastocysts obtained on day 7 after IVF were incubated in TCM199 with $1 \%$ Triton $\mathrm{X}-100$ and $100 \mu \mathrm{g} / \mathrm{mL}$ propidium iodide for 30 seconds. Subsequently, the blastocysts were incubated for 15 min in PBS containing 4\% paraformaldehyde and $10 \mu \mathrm{g} / \mathrm{mL}$ Hoechst 33342. Then, the embryos were washed in PBS and placed on glass slides with glyceroland covered with a coverslip, as described by Iwasaki et al. (1990). To determine all rates (NMR, CMR, CR and BR) the quantity of identified structures (mature/cleaved/blastocyst) was considered in relation to the total number of initial structures (immature oocytes).

The experimental design was randomized in a factorial arrangement and statistical model considered the fixed effects (culture medium and maturation time) and their interactions on variables NMR, CMR, CR, BR, cell number of ICM, TE and ICM + TE (total cell number). Data were analyzed by least squares method of GLM proc (SAS, version 9.0) and means were compared by Tukey's test $(\mathrm{P}<0.05)$.

\section{Results and Discussion}

The meiotic progression was affected when FF was added to TCM199 medium, detected by a gradual reduction in nuclear maturation rate as the concentration $\mathrm{FF}$ in TCM199 medium increased $(\mathrm{P}<0.05)$. The culture media without FF (TCM 199) and supplemented with $25 \%$ FF (TCM $199+25 \% \mathrm{FF}$ ) were superior compared with pure FF $(\mathrm{P}<0.05)$, except for the maturation time of 28 hours, in which all groups were similar. Conversely, the nuclear maturation rate obtained with TCM $199+25 \% \mathrm{FF}$ and TCM $199+50 \%$ FF were similar to that observed for TCM199 at all maturation times analyzed. The lowest rate obtained at $22 \mathrm{~h}$ of maturation in pure $\mathrm{FF}(\mathrm{P}<0.05)$ revealed the interaction between concentration and maturation time on nuclear maturation (Table 1).

Considering that the major nuclear changes occur during oocyte maturation, the assessment of nuclear maturation rate is a useful tool to evaluate oocyte competence (Pereira et al., 2010; Prentice et al., 2011). In horses, Dell'Aquila et al. (1997) and Bøgh et al. (2002), using $100 \% \mathrm{FF}$, found nuclear maturation rates of 68.5 and $79 \%$, respectively. In the present study, pure FF provided lower rates, ranging from 43 to $65 \%$, similar to the reports of Avery et al. (2003) and Coleman et al. (2007), who describe nuclear maturation rates of 41 and $44 \%$, respectively, in cattle.

Yet, an inverse relationship occurred between FF concentration and NMR in all maturation times; the lowest rate obtained in short maturation time indicated an interaction between FF concentration and maturation time on the NMR. Avery et al. (2003) and Coleman et al. (2007) also observed interaction of maturation time with the concentration between FF on nuclear maturation rate.

The nuclear maturation rates achieved at $28 \mathrm{~h}$ of maturation in media containing high concentrations of $\mathrm{FF}$ (75 or $100 \%$ ) were greater than those observed in other maturation times, possibly due to the delay of meiotic progression caused by $\mathrm{FF}$, which provided additional time for the oocytes to acquire competence (Pereira et al., 2010; Prentice et al., 2011; Gottardi et al., 2012). According to Aguilar et al. (2001), a slower nuclear maturation provides

Table 1 - Nuclear maturation rate of bovine oocytes matured in vitro for four different maturation times in culture media containing different concentrations of follicular fluid

\begin{tabular}{|c|c|c|c|c|c|c|c|c|}
\hline \multirow{3}{*}{ Medium } & \multicolumn{8}{|c|}{ Nuclear maturation rate } \\
\hline & \multicolumn{2}{|c|}{$22 \mathrm{~h}^{1}$} & \multicolumn{2}{|c|}{$24 \mathrm{~h}^{1}$} & \multicolumn{2}{|c|}{$26 \mathrm{~h}^{1}$} & \multicolumn{2}{|c|}{$28 \mathrm{~h}^{1}$} \\
\hline & $\mathrm{N}$ & NMR (\%) & $\mathrm{N}$ & NMR (\%) & $\mathrm{N}$ & NMR (\%) & $\mathrm{N}$ & NMR $(\%)$ \\
\hline TCM199 & 91 & $72.53 \mathrm{Aa}$ & 84 & $78.13 \mathrm{Aa}$ & 87 & $77.14 \mathrm{Aa}$ & 102 & $82.35 \mathrm{Aa}$ \\
\hline $\mathrm{TCM} 199+25 \% \mathrm{FF}$ & 94 & $68.27 \mathrm{Aba}$ & 79 & $77.42 \mathrm{Aa}$ & 84 & $79.79 \mathrm{Aa}$ & 91 & $75.70 \mathrm{Aa}$ \\
\hline TCM $199+50 \%$ FF & 112 & 66.96Aba & 77 & $70.11 \mathrm{Aba}$ & 93 & $74.76 \mathrm{Aa}$ & 83 & $69.39 \mathrm{Aa}$ \\
\hline TCM $199+75 \% \mathrm{FF}$ & 95 & $54.13 \mathrm{BCc}$ & 88 & 61.32BCbc & 81 & 69.39Aab & 87 & $72.90 \mathrm{Aa}$ \\
\hline $100 \% \mathrm{FF}$ & 116 & $43.10 \mathrm{Cb}$ & 77 & $52.58 \mathrm{Cab}$ & 70 & $59.79 \mathrm{Ba}$ & 106 & $65.89 \mathrm{Aa}$ \\
\hline
\end{tabular}

${ }^{1}$ In vitro maturation time.

NMR - nuclear maturation rate; FF - follicular fluid.

ABC Different capital letters, in the same column, indicate difference by Tukey's test $(\mathrm{P}<0.05)$.

abc Different small letters, in the same row, indicate difference by Tukey's test $(\mathrm{P}<0.05)$. 
oocytes with more time to synthesize, modify and store new proteins and ribonucleoproteins, and therefore enhances their competence. Moreover, despite the higher nuclear maturation rate observed when the maturation time was extended, the rates obtained with pure FF remained lower than those with TCM199 medium.

The migration of CG was influenced by the FF concentration only at 24 of maturation. At this maturation time, there was a gradual decrease in the cytoplasmic maturation rate (CMR) to the extent that $\mathrm{FF}$ concentration was rising (Table 2). The CMR reached with $25 \% \mathrm{FF}$ was similar to those obtained in TCM199 medium at 22, 26 and $28 \mathrm{~h}$ of maturation. At $22 \mathrm{~h}$ of maturation, the CMR was lower than those observed in all other maturation times $(\mathrm{P}<0.05)$.

Mammalian CG first appears in the early stages of oocyte growth. However, the exact time window in which CG are synthesized differs among species. The CG migration is an important step in cytoplasmic maturation and has been used routinely as a criterion in assessing the maturity and organelle organization of developing oocytes (Liu, 2011). A recent study revealed that FF promotes oocyte cytoplasmic maturation during IVM and suggested that the major role of $\mathrm{FF}$ is to provide protection against oxidative stress (Grupen and Armstrong, 2010). Several FF components, including amino acids (Hong and Lee, 2007) and plasminogen activators and plasmin (Papanikolaou et al., 2008) have been found to exert positive effects on porcine oocyte cytoplasmic maturation in vitro.

The results of the present study showed that FF interferes with oocyte maturation by slowing the migration of CG to the periphery of the oocyte, causing a delay in cytoplasmic maturation and possibly providing more adherence time to cells of COC. Even though the cytoplasmic maturation delay promoted by FF might be beneficial to oocytes, a previous study suggests that delayed cytoplasmic maturation is responsible for the abnormalities observed during fertilization and in vitro development, which commonly involved the migration and dispersal of CG (Damiani et al., 1996).

It is likely that steroids, gonadotrophins and the maturation medium itself all play an important role, particularly if the oocytes are matured in defined or semi-defined culture media (Accardo et al., 2004). Follicle-stimulating hormone (FSH) maintained associations between growing oocytes and cumulus cells during in vitro growth culture, probably by supporting the oocytes (Cayo-Colca et al., 2011). The FSH:Luteinizing hormone (LH) ratio in IVM culture media is directly correlated with oocyte cytoplasmic maturation (Sha et al., 2010). Schoevers et al. (2003), using porcine oocytes, stated that FSH initially retards germinal vesicle breakdown, but overall has a stimulatory effect on nuclear and cytoplasmic maturation. Considering the strategic role of FF on in vitro cytoplasmic maturation (Grupen and Armstrong, 2010), the delay in cytoplasmic maturation verified in the present study may have occurred due to insufficient concentration of FSH, since the FSH concentration was not adjusted when the FF concentration was increased.

The fertilization moment influenced cleavage (CR) and blastocyst rates (BR). Cleavage rate and BR obtained at $28 \mathrm{~h}$ were lower than those achieved at $24 \mathrm{~h}$ and $26 \mathrm{~h}$, in all maturation media $(\mathrm{P}<0.05)$. On the other hand, when fertilization was performed at 24 or $26 \mathrm{~h}$, the FF concentration influenced $\mathrm{CR}$ and $\mathrm{BR}$, which were lower when higher concentrations $(\geq 75 \%)$ were used $(\mathrm{P}<0.05)$. Follicular fluid concentration negatively affected BR when the fertilization was performed at $28 \mathrm{~h}$; however, it had no influence on CR (Table 3).

Contrary to the present results, Avery et al. (2003) obtained unsatisfactory cleavage rates (around 9\%) when using pure FF. These researchers attributed the low cleavage rates to the ability of $\mathrm{FF}$ to cause adhesion of solids to cumulus cells, forming a physical barrier that hinders the penetration of sperm. These findings suggest that FF at high concentrations might negatively influence adhesion to the

Table 2 - Cytoplasmic maturation rate of bovine oocytes matured in vitro for four different maturation times in culture media containing different concentrations of follicular fluid

\begin{tabular}{|c|c|c|c|c|c|c|c|c|}
\hline \multirow{3}{*}{ Medium } & \multicolumn{8}{|c|}{ Cytoplasmic maturation rate } \\
\hline & \multicolumn{2}{|c|}{$22 \mathrm{~h}^{1}$} & \multicolumn{2}{|c|}{$24 \mathrm{~h}^{1}$} & \multicolumn{2}{|c|}{$26 \mathrm{~h}^{1}$} & \multicolumn{2}{|c|}{$28 \mathrm{~h}^{1}$} \\
\hline & $\mathrm{N}$ & CMR (\%) & $\mathrm{N}$ & CMR (\%) & $\mathrm{N}$ & CMR (\%) & $\mathrm{N}$ & CMR (\%) \\
\hline TCM199 & 72 & $6.94 \mathrm{Ab}$ & 74 & $52.70 \mathrm{Aa}$ & 75 & $56.00 \mathrm{Aa}$ & 76 & $61.84 \mathrm{Aa}$ \\
\hline $\mathrm{TCM} 199+25 \% \mathrm{FF}$ & 69 & $7.25 \mathrm{Ac}$ & 70 & $31.43 \mathrm{Bb}$ & 72 & $44.44 \mathrm{Ab}$ & 73 & $68.49 \mathrm{Aa}$ \\
\hline $\mathrm{TCM} 199+50 \% \mathrm{FF}$ & 73 & $4.11 \mathrm{Ac}$ & 73 & $9.59 \mathrm{Cbc}$ & 73 & $31.51 \mathrm{Ab}$ & 75 & $62.67 \mathrm{Aa}$ \\
\hline TCM $199+75 \% \mathrm{FF}$ & 72 & $5.56 \mathrm{Ab}$ & 72 & $11.11 \mathrm{BCb}$ & 75 & $30.67 \mathrm{Ab}$ & 73 & $69.86 \mathrm{Aa}$ \\
\hline $100 \% \mathrm{FF}$ & 73 & $2.74 \mathrm{Ac}$ & 69 & $11.59 \mathrm{BCbc}$ & 75 & $29.33 \mathrm{Ab}$ & 76 & $64.47 \mathrm{Aa}$ \\
\hline
\end{tabular}

${ }^{1}$ In vitro maturation time.

CMR - cytoplasmic maturation rate; FF - follicular fluid.

ABC Different capital letters, in the same column, indicate difference by Tukey's test $(\mathrm{P}<0.05)$.

abc Different small letters, in the same row, indicate difference by Tukey's test $(\mathrm{P}<0.05)$. 
COC cells. In the present study, however, the use of heparin with subsequent FF filtering probably prevented the solid accumulation to $\mathrm{COC}$, and allowed adequate fertilization.

The low blastocyst rates obtained when fertilization was performed at $28 \mathrm{~h}$ of IVM might be explained by the fact that fertilization does not occur immediately after insemination. According to Méo et al. (2007), the pronuclei first appear $12 \mathrm{~h}$ after insemination. Thus, oocytes inseminated later (28 h) would have missed the optimal moment for fertilization due to aging. Moreover, since aged oocytes ( $28 \mathrm{~h}$ of IVM) are more susceptible to spontaneous parthenogenetic activation (Shirazi et al., 2009), the cleavage rates obtained probably include parthenogenetically activated zygotes.

The FF concentration affected ICM cell number and the total cell number, when fertilization was performed at 24 and 26 h IVM, respectively $(\mathrm{P}<0.05)$; in both cases, the medium TCM199 + 50\% FF was higher than others $(\mathrm{P}<0.05)$. The ICM cell number was similar for all culture media, when the fertilization was performed at $26 \mathrm{~h}$ IVM. The TE cell number was not affected by addition of the $\mathrm{FF}$, but it was influenced by the moment of fertilization in TCM199 $+50 \% \mathrm{FF}$, given that cell numbers at $26 \mathrm{~h}$ IVM were higher than at $24 \mathrm{~h}$ IVM $(\mathrm{P}<0.05)$. The total cell number $(\mathrm{ICM}+\mathrm{TE})$ was influenced by the fertilization moment, regardless of maturation medium $(\mathrm{P}<0.05)$. The $\mathrm{FF}$, in the $50 \%$ concentration, increased the total cell number when fertilization was performed at $26 \mathrm{~h}$ IVM (Table 4).
According to Dulcibella et al. (1990) and Fissore et al. (2002), during the aging process, progressive deterioration of the oocyte occurs, including the rupture of mitochondrial membranes and inability to generate ATP. The dramatic decrease in CG release affects cell proliferation and survival. It is important to point out that oocytes subjected to IVM have a higher energy demand, which contributes to greater damage due to aging (Prentice et al., 2011). The satisfactory blastocyst rates obtained with TCM199 medium $+25 \% \mathrm{FF}$ in maturation times of 24 or $26 \mathrm{~h}$ may have been due to the ability of FF to create an environment for oocytes that made them suitable for further in vitro embryo development, by modulating the progression of CG.

Considering that follicular modifications occur gradually in the in vivo environment, the low blastocyst rates obtained using $\mathrm{FF}$ concentrations $\geq 50 \%$ might be explained by the sudden change of media in the in vitro environment. This abrupt environmental change probably caused veering in oocyte metabolic pathways, negatively interfering with the maturation process. These results agree with those of Elmileik et al. (1995) and Kim et al. (1996), who pointed out that FF at concentrations of 50 or $60 \%$ have an adverse effect on embryo development. Another explanation for the low blastocyst rate might be the negative action of a specific fatty acid present in FF. The linoleic, oleic, stearic and palmitic fatty acids are the most prevalent in bovine FF (Bender et al., 2010). However, the increase in palmitic

Table 3 - Cleavage and blastocyst rates of bovine oocytes fertilized at three different moments of in vitro maturation in culture media containing different concentrations of follicular fluid

\begin{tabular}{|c|c|c|c|c|c|c|c|c|c|}
\hline \multirow{3}{*}{ Medium } & \multicolumn{9}{|c|}{ Cleavage and blastocyst rates } \\
\hline & \multicolumn{3}{|c|}{$24 \mathrm{~h}^{1}$} & \multicolumn{3}{|c|}{$26 \mathrm{~h}^{1}$} & \multicolumn{3}{|c|}{$28 \mathrm{~h}^{1}$} \\
\hline & $\mathrm{N}$ & CR $(\%)$ & $\mathrm{BR}(\%)$ & $\mathrm{N}$ & CR $(\%)$ & $\mathrm{BR}(\%)$ & $\mathrm{N}$ & CR $(\%)$ & BR $(\%)$ \\
\hline TCM199 & 375 & $90.13 \mathrm{Aa}$ & $35.73 \mathrm{Aa}$ & 379 & $90.77 \mathrm{Aa}$ & $33.77 \mathrm{Aa}$ & 187 & $55.61 \mathrm{Ab}$ & $12.83 \mathrm{ABb}$ \\
\hline $\mathrm{TCM} 199+25 \% \mathrm{FF}$ & 384 & $89.32 \mathrm{Aa}$ & $41.41 \mathrm{Aa}$ & 395 & $90.63 \mathrm{Aa}$ & $38.73 \mathrm{Aa}$ & 191 & $53.40 \mathrm{Ab}$ & $14.14 \mathrm{Ab}$ \\
\hline $\mathrm{TCM} 199+50 \% \mathrm{FF}$ & 408 & $87.75 \mathrm{Aa}$ & $17.65 \mathrm{Ba}$ & 401 & $88.28 \mathrm{Aa}$ & $18.45 \mathrm{Ba}$ & 189 & $49.74 \mathrm{Ab}$ & 8.47Aba \\
\hline TCM199+ 75\%FF & 243 & $81.89 \mathrm{Ba}$ & $16.46 \mathrm{Ca}$ & 241 & $81.74 \mathrm{Ba}$ & $17.01 \mathrm{Ca}$ & 186 & $43.01 \mathrm{Ab}$ & $7.53 \mathrm{Aba}$ \\
\hline $\mathrm{FF}$ & 242 & $82.64 \mathrm{Ba}$ & $11.57 \mathrm{Ca}$ & 239 & $80.75 \mathrm{Ba}$ & $13.39 \mathrm{Ca}$ & 183 & $37.70 \mathrm{Ab}$ & $3.83 \mathrm{Bb}$ \\
\hline
\end{tabular}

${ }^{1}$ In vitro fertilization moment.

$\mathrm{CR}$ - cleavage rate; BR - blastocyst rate; FF - follicular fluid.

ABC Different capital letters, in the same column, indicate difference by Tukey test $(\mathrm{P}<0.05)$.

abc Different small letters, in the same row, indicate difference by Tukey test $(\mathrm{P}<0.05)$

Table 4 - Number of inner cell mass, trophectoderm cell and total cells in bovine embryos fertilized at two moments after in vitro maturation and cultured for seven days in culture media containing different concentrations of follicular fluid

\begin{tabular}{|c|c|c|c|c|c|c|}
\hline \multirow{3}{*}{ Medium } & \multicolumn{6}{|c|}{ Cell number of ICM, TE and Total } \\
\hline & \multicolumn{2}{|c|}{$\mathrm{ICM}$} & \multicolumn{2}{|c|}{ TE } & \multicolumn{2}{|c|}{$\mathrm{ICM}+\mathrm{TE}$} \\
\hline & $24 \mathrm{~h}^{1}$ & $26 \mathrm{~h}^{1}$ & $24 \mathrm{~h}^{1}$ & $26 \mathrm{~h}^{*}$ & $24 \mathrm{~h}^{1}$ & $26 \mathrm{~h}^{1}$ \\
\hline TCM199 & $29.91 \pm 3.83 \mathrm{Ba}$ & $34.84 \pm 3.78 \mathrm{Aa}$ & $67.93 \pm 3.78 \mathrm{Aa}$ & $74.69 \pm 2.02 \mathrm{Aa}$ & $97.84 \pm 5.70 \mathrm{Ab}$ & $109.53 \pm 4.24 \mathrm{Ba}$ \\
\hline TCM199+25\%FF & $28.87 \pm 0.83 \mathrm{Bb}$ & $36.29 \pm 1.46 \mathrm{Aa}$ & $67.98 \pm 3.91 \mathrm{Aa}$ & $75.73 \pm 3.32 \mathrm{Aa}$ & $96.84 \pm 4.85 \mathrm{Ab}$ & $112.02 \pm 3.98 \mathrm{Aba}$ \\
\hline TCM199+50\%FF & $35.49 \pm 1.46 \mathrm{Aa}$ & $40.04 \pm 2.80 \mathrm{Aa}$ & $72.51 \pm 3.32 \mathrm{Ab}$ & $80.62 \pm 5.87 \mathrm{Aa}$ & $108.00 \pm 3.98 \mathrm{Ab}$ & $120.67 \pm 7.96 \mathrm{Aa}$ \\
\hline
\end{tabular}

${ }^{1}$ In vitro fertilization moment.

ICM - inner cell mass; TE - trophectoderm; FF - follicular fluid.

$\mathrm{ABC}$ Different capital letters, in the same column, indicate difference by Tukey's test $(\mathrm{P}<0.05)$.

abc Different small letters, in the same row, indicate difference by Tukey's test $(\mathrm{P}<0.05)$. 
acid during IVM has a detrimental effect on the blastocyst rate (LeRoy et al., 2005).

Similar to what happened with the cleavage rate, the low blastocyst rates observed when fertilization was performed at $28 \mathrm{~h}$ probably resulted from oocyte aging. According to Souza et al. (2009), although aged oocytes can be fertilized and initiate embryo development, they may not reach the blastocyst stage due to fertilization failure. At the moment of spermatozoa penetration into the aged oocyte, signaling can occur because of the influx of calcium ions, which acts inducing apoptosis, thus stopping embryo development. The results of the present study corroborate the oocyte aging theory, since, regardless of the FF concentration used, the blastocyst rates were unsatisfactory when fertilization occurred at the later time $(28 \mathrm{~h})$.

Romero-Arredondo and Seidel (1996) observed that supplementation of maturation medium with FF improves the developmental capacity in bovine oocytes and consequently enhances embryonic development. This is corroborated by the results found in the present study, in which the addition of FF to the maturation medium proved beneficial. We found that FF added to TCM199 medium at a concentration of $50 \%$ allowed the collection of embryos with higher ICM cell number than the other media. This increase in ICM cell number might be caused by the greater availability of nutrients in FF, including essential amino acids.

Initial approaches to metabolic profiling of $\mathrm{FF}$ indicate a relationship between FF amino acid concentrations and oocyte cleavage following IVF, particularly L-alanine and glycine, which are two of the most abundant amino acids in bovine FF (Sinclair et al., 2008; Bender et al., 2010). The supplementation of alanine and glycine in the culture medium synergistically improves development of in vitroproduced bovine embryos and increases blastocyst cell numbers (Lee and Fukui, 1996). Thus, the increase in total cell number verified in the present study might indicate that the addition of FF to the TCM199 medium improves embryonic quality.

\section{Conclusions}

Although higher concentrations of follicular fluid added to the maturation medium reduce embryonic development, at lower concentrations follicular fluid slows meiotic progression and migration of cortical granules, and this contributes to increased number of cells in inner cell mass. Thus, follicular fluid added to the maturation medium at lower concentrations enhances the total cell numbers in bovine embryos produced in vitro, especially regarding inner cell mass cells.

\section{Acknowledgments}

The authors would like to thank Prof. PhD Russel J. Reiter (University of Texas Health Science Center, San Antonio, USA) and Prof. PhD Claudia Lima Verde Leal (Universidade de São Paulo, Pirassununga, Brazil), for reviewing this manuscript; and $\mathrm{PhD}$ Milton Rezende Teixeira Neto for the valuable assistance in data analysis.

\section{References}

Accardo, C.; Dattena, M.; Pilichi, S.; Maraa, L.; Chessa, B. and Cappai, P. 2004. Effect of recombinant human FSH and LH on in vitro maturation of sheep oocytes; embryo development and viability. Animal Reproduction Science 81:77-86.

Aguilar, J.; Woods, G.; Miragaya, M.; Olsen L. and Vanderwall, D. 2001. Effect of homologous preovulatory follicular fluid on in vitro maturation of equine cumulus-oocyte complexes. Theriogenology $56: 745-748$.

Albuz, F. K.; Sasseville, M.; Lane, M.; Armstrong, D. T.; Thompson, J. G. and Gilchrist, R. B. 2010. Simulated physiological oocyte maturation (SPOM): a novel in vitro maturation system that substantially improves embryo yield and pregnancy outcomes. Human Reproduction 73:1-13.

Algriany, O.; Bevers, M.; Schoevers, E.; Colenbrander, B. and Dieleman, S. 2004. Follicle size-dependent effects of sow follicular fluid on in vitro cumulus expansion, nuclear maturation and blastocyst formation of sow cumulus oocytes complexes. Theriogenology 62:1483-1497.

Avery, B.; Strobech, L.; Jacobsen, T.; Bogh, I. and Greve, T. 2003. In vitro maturation of bovine cumulus-oocyte complexes in undiluted follicular fluid effect on nuclear maturation, pronucleus formation and embryo development. Theriogenology 59:987-999.

Bender, K.; Walsh, S.; Evans, A.; Fair, T. and Brennan, L. 2010. Metabolite concentrations in follicular fluid may explain differences in fertility between heifers and lactating cows. Reproduction 139:1047-1055.

Bevers, M. M.; Dieleman, S. J.; Van der Hurk, R. and Izadyar, F. 1997. Regulation and modulation of oocyte maturation in the bovine. Theriogenology 47:13-22.

Bøgh, I. B.; Bézard, J.; Duchamp, G.; Baltsen, M.; Gerard, N.; Daeles, P. and Greve, T. 2002. Pure preovulatory follicular fluid promotes in vitro maturation of in vivo aspirated equine oocytes. Theriogenology 57:1765-1779.

Brevini, T.; Cillo, F.; Antonini, S. and Gandolfi, F. 2007. Cytoplasmic remodelling and the acquisition of developmental competence in pig oocytes. Animal Reproduction Science 98:23-28.

Cayo-Colca, I.; Yamagami, Y.; Phan, T. and Miyano, T. 2011. A combination of FSH and dibutyryl cyclic AMP promote growth and acquisition of meiotic competence of oocytes from early porcine antral follicles. Theriogenology 75:1602-1612.

Cherr, G. N.; Drobnis, E. Z. and Katz, D. F. 1988. Localization of cortical granule constituents before and after exocytosis in the hamster egg. Journal of Experimental Zoology 246:81-93.

Choi, Y. H.; Takagi, M. and Kamishita, H. 1998. Developmental capacity of bovine oocytes matured in two kinds of follicular fluid and fertilized in vitro. Animal Reproduction Science 50:27-33.

Coleman, N.; Shagiakmetova, G.; Lebedeva, I.; Lebedeva, I.; Kuzmina, T. and Golubev, A. 2007. In vitro maturation and early developmental capacity of bovine oocytes cultured in 
pure follicular fluid and supplementation with follicular wall. Theriogenology 67:1053-1059.

Damiani, P.; Fissore, R. A.; Cibelli, J. B.; Long, C.; Balise, J.; Robl, J. and Duby, R. 1996. Evaluation of developmental competence, nuclear and ooplasmic maturation of calf oocytes. Molecular Reproduction Development 45:521-534.

Dell'Aquila, M.; Cho, Y.; Minoia, P.; Traina, V.; Lacalandra, G. and Maritato, F. 1997. Effects of follicular fluid supplementation of in-vitro maturation medium on the fertilization and development of equine oocytes after in-vitro fertilization or intracytoplasmic sperm injection. Human Reproduction 12:2266-2272.

Ducolomb, Y.; González-Márquez, H.; Fierro, R.; Fierro, R.; Jimenez, I.; Casas, E.; Flores, D.; Bonilla, E.; Salazar, Z. and Bitancourt, M. 2013. Effect of porcine follicular fluid proteins and peptides on oocyte maturation and their subsequent effect on in vitro fertilization. Theriogenology 79:896-904.

Dulcibella, T.; Duffy, P.; Reindollar, R. and Su, B. 1990. Changes in the distribution of mouse oocyte cortical granules and ability to undergo the cortical reaction during gonadotropin stimulated meiotic maturation and aging in vivo. Biology of Reproduction 43:870-876.

Elmileik, A.; Maeda, T. and Terada, T. 1995. Higher rates of development into blastocyst following the in vitro fertilization of bovine oocytes matured in a medium supplemented with the fluid from large bovine follicles. Animal Reproduction Science 38:85-96

Fissore, R.; Kurokawa, M.; Knott, J.; Kurokawa, M.; Knott, J.; Zhang, M. and Smyth, J. 2002. Mechanisms underlying oocyte activation and postovulatory ageing. Reproduction 124:745-754.

Gilchrist, R. B. and Thompson, J. G. 2007. Oocyte maturation: emerging concepts and technologies to improve developmental potential in vitro. Theriogenology 67:6-15.

Gonçalves, P. B. D.; Barreta, M. H.; Siqueira, L. C. and Antoniazzi, A. Q. 2008. Biotecnologias da reprodução animal. Ciência Veterinária nos Trópicos 11:135-138.

Gottardi, F.; Barreto, L.; Gonçalves, F. and Perril, S. 2012. Effects of cumulus cells and cysteamine during bovine oocyte in vitro maturation on meiosis progression and acquisition of developmental competence. Arquivo Brasileiro de Medicina Veterinária e Zootecnia 64:245-252.

Grupen, C. and Armstrong, D. 2010. Relationship between cumulus cell apoptosis, progesterone production and porcine oocyte developmental competence: temporal effects of follicular fluid during IVM. Reproduction, Fertility and Development 22:1100-1109.

Hong, J. and Lee, E. 2007. Intrafollicular amino acid concentration and the effect of amino acids in a defined maturation medium on porcine oocyte maturation, fertilization, and preimplantation development. Theriogenology 68:728-335.

Hosoe, M. and Shioya, Y. 1997. Distribution of cortical granules in bovine oocytes classified by cumulus complex. Zygote 5:371-376.

Hussein, T. S.; Thompson, J. G. and Gilchrist, R. B. 2006. Oocytesecreted factors enhance oocyte developmental competence. Developmental Biology 296:514-521.

Iwasaki, S.; Yoshiba, N.; Ushijima, H.; Watanabe, S. and Nakahara, T. 1990. Morphology and proportion of inner cell mass of bovine blastocysts fertilized in vitro and in vivo. Journal of Reproduction and Fertility 90:279-285.

Kim, K.; Mitsumizo, N.; Fujita, K. and Utsumi, K. 1996. The effects of follicular fluid on in vitro maturation, oocyte fertilization and the development of bovine embryos. Theriogenology 45:787-799.
Lee, E. and Fukui, Y. 1996. Synergistic effect of alanine and glycine on bovine embryos cultured in a chemically defined medium and amino acid uptake by vitro-produced bovine morulae and blastocysts. Biology of Reproduction 55:1383-1389.

Leroy, J. L. M. R.; Vanholder, T.; Mateusen, B.; Christophe, A.; Opsomer, G.; de Kruif, A.; Genicot, G. and Van Soom, A. 2005. Non-esterified fatty acids in follicular fluid of dairy cows and their effect on development capacity of bovine oocytes in vitro. Reproduction 130:485-495.

Liu, L.; Trimarchi, J. R.; Navarro, P.; Blasco, M. A. and Keefe, D. L. 2003. Oxidative stress contributes to arsenic-induced telomere sttrition, chromosome instability and apoptosis. The Journal Biology Chemistry 278:31998-32004.

Liu, M. 2011. The biology and dynamics of mammalian cortical granules. Reproductive Biology and Endocrinology 9:149.

Méo, S. C.; Yamazaki, W.; Ferreira, C. R.; Perecin, F.; Saraiva, N. Z.; Leal, C. L. and Garcia, J. M. 2007. Parthenogenetic activation of bovine oocytes using single and combined strontium, ionomycin and 6-dimethylaminopurine treatments. Zygote 15:295-306.

Papanikolaou, T.; Amiridis, G.; Dimitriadis, I.; Vainas, E. and Rekkas, C. 2008. Effect of plasmin, plasminogen activators and a plasmin inhibitor on bovine in vitro embryo production. Reproduction, Fertility and Development 20:320-327.

Pereira, M.; Costa, F.; Oliveira, A.; Serapião, R.; Machado, M.; Viana, J. and Camargo, L. 2010. Quantificação de transcritos maternos em oócitos bovinos submetidos a diferentes condições de maturação. Arquivo Brasileiro de Medicina Veterinária e Zootecnia 62:1394-1400.

Prentice, J.; Singh, J.; Dochi, O. and Anzar, M. 2011. Factors affecting nuclear maturation, cleavage and embryo development of vitrified bovine cumulus-oocyte complexes. Theriogenology 75:602-609.

Rizos, D.; Ward, F.; Duffy, P.; Boland, M. and Lonergan, P. 2002. Consequences of bovine oocyte maturation, fertilization or early embryo development in vitro versus in vivo: implications for blastocyst yield and blastocyst quality. Molecular Reproduction Development 61:234-248.

Romero-Arredondo, A. and Seidel, G. 1996. Effects of follicular fluid during in vitro maturation of bovine oocytes on in vitro fertilization and early embryonic development. Biology of Reproduction 55:1012-1016.

Schoevers, E.; Kidson, A.; Verheijden, J. and Bevers, M. 2003. Effect of follicle-stimulating hormone on nuclear and cytoplasmic maturation of sow oocytes in vitro. Theriogenology 59:2017-2028.

Sha, W.; Xu, B.; Li, M.; Liu, D.; Feng, H. and Sun, Q. 2010. Effect of gonadotropins on oocyte maturation in vitro: an animal model. Fertility and Sterility 93:1650-1661.

Shirazi, A.; Bahiraee, A.; Ahmadi, E.; Nazari, H.; Heidari, B. and Borjian, S. 2009. The effect of the duration of in vitro maturation (IVM) on parthenogenetic development of ovine oocytes. Avicenna Journal of Medical Biotechnology 1:181-191.

Sinclair, K.; Lunn, L.; Kwong, W.; Wonnacot, K.; Linforth, R. and Craigon, J. 2008. Amino acid and fatty acid composition of follicular fluid as predictors of in vitro embryo development. Reproductive BioMedicine Online 16:859-868.

Sirard, M.; Roy, F.; Patrick, B.; Merrimilod, P. and Guilbault, L. 1995. Origin of the follicular fluid added to the media during bovine IVM influences embryonic development. Theriogenology 44:25-94.

Sirard, M. A.; Desrosier, S. and Assidi, M. 2007. In vivo and in vitro effects of FSH on oocyte maturation and developmental competence. Theriogenology 68:71-76.

Souza, F.; Canisso, I. and Osório, J. 2009. Algumas particularidades no envelhecimento do gameta feminino. Revista Acadêmica: Ciências Agrárias e Ambientais 7:273-279. 